\title{
NEUE FULDAER BRUCHSTÜCKE
}

\author{
DER

\section{WEINGARTENER PROPHETENHANDSCHRIFT}

\author{
HERAUSGEGEBEN VON \\ Dr. CARL SCHERER \\ OBERBIBLIOTHEKAR IN FULDA
}

MIT EINER TAFEL

SONDERABDRUCK AUS DER ZEITSCHRIFT FÜR DIE ALTTESTAMENTLICHE WISSENSCHAFT

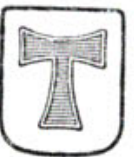

VERLAG VON ALFRED TÖPELMANN (VORMALS J. RICKER) * GIESSEN * 1910 
